\title{
OBITUARY
}

Erwin O. Alt

\section{Obituary W. Sandhas}

Published online: 6 December 2021

(C) The Author(s), under exclusive licence to Springer-Verlag GmbH Austria, part of Springer Nature 2021

\section{Brief Vita:}

Born April 141934 in Berlin, Germany, he studied physics at the Freie Universität Berlin, finishing with a Ph.D. in 1963. After a short PostDoc period he moved for a PostDoc position to the Physikalisches Institut of Bonn University where he made his habilitation in 1967. In 1969 he became Full Professor at the Institut für Physik of Mainz University where he stayed for four years. In 1973 he moved back to a chair in Bonn. Emerited in 1999. Deceased August 252021.

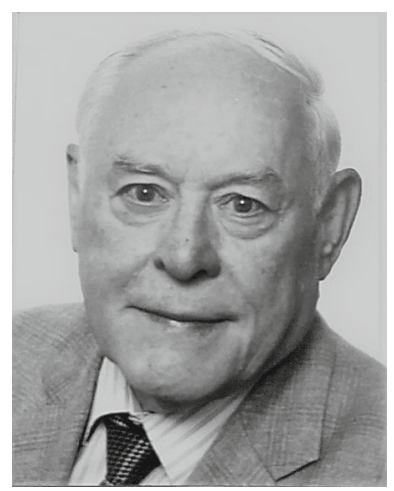

From the beginning his interest lay in various aspects of non-relativistic scattering theory, both fundamental as well as practical. In the first category fall a proof of the existence of Moller operators for singular potentials (with collaborator) and multichannel scattering states. However, the most enduring impact he exerted through the results of his longstanding and very successful research activity on the foundation and formulation of a practical theory of non-relativistic few body scattering, both for neutral and charged particles (with several collaborators). They led to an enormous flourishing of the few body field and still continue to strongly influence present research. But he was also very active in pursuing investigations of concrete nuclear, atomic and molecular few body processes. For this purpose he worked together with many colleagues from-among others-the universities of Bonn, Mainz, Pretoria, Providence, and research institutes such as Los Alamos National Laboratory and Joint Institute of Nuclear Research Dubna.

Because of his ability to communicate complicated issues in a clear and intuitive manner he was invited as speaker to numerous institutes and conferences. This capability and his pedagogical skills also attracted many students several of whom could successfully pursue a scientific career.

In memoriam of Werner Sandhas Prof. Dr. Dr. hc.

E. O. Alt (ه)

Institut für Physik, Universität Mainz, Staudingerweg 7, 55128 Mainz, Germany

E-mail: erwin.alt@uni-mainz.de 
In recognition of his scientific achievements he was honored with several awards, among them in 2004 with a Dr. hc of the Joint Institute of Nuclear Research.

With his passing away not only his many friends and collaborators, but the whole few body community has lost one of its most prominent and inspiring members.

Acknowledgements The author is grateful to Mrs. Helga and Silvia Sandhas for providing biographical data and the photo.

Publisher's Note Springer Nature remains neutral with regard to jurisdictional claims in published maps and institutional affiliations. 